\title{
Ultrasound as pretreatment in biogas production from crude glycerol
}

\author{
Zschach LG*§, Kreutz C† and E Martins RJ§‡ \\ *National University of Misiones, Misiones, Argentina. \$Polytechnic Institute of Bragança, \\ Bragança, Portugal. †Federal University of Technology, Paraná, Brazil. łUniversity of Porto, \\ Porto, Portugal.
}

\begin{abstract}
Air pollution, acid precipitation, ozone depletion and the gaseous emissions to the atmosphere are associated to the petroleum derivate use, currently considered the main energy source used in the world. Renewable energy sources are expected to replace them in order to solve these environmental concerns. Biofuels as biodiesel and biogas are renewable energy produced from natural matter. Studies made suggest that using the principal by-product of biodiesel's production process, crude glycerol, is possible to obtain biogas. Biogas can be produced from an anaerobic digestion process and enhanced by using pretreatment in substrate. This work tested ultrasound pretreatment on crude glycerol as a substrate in the biogas production. Different times of pretreatment (15 and 30 minutes) were examined, to determinate the best performance and compare it to the untreated substrate. The biogas production was daily measured directly from the reactors. The results showed that ultrasound pretreatment improved methane production. The best result was obtained by using 30 minutes of pretreatment on crude glycerol.
\end{abstract}

Keywords. Ultrasound pretreatment, anaerobic digestion, crude glycerol.

Introduction. Global energy supply is based on petroleum derivative. Studies made about this source suggest that it causes several environmental concerns as air pollution, acid precipitation and gas emissions to the atmosphere (1). In the interest of solving energy supply problems, the changes involved include to create energy savings on the demand side, improve the production process efficiency and replace petroleum derivate by renewable energy (2). Biofuels are considered a renewable energy source produced from natural matter. They can be solids as biochar, liquid as ethanol or biodiesel or gaseous as biogas (3).

Crude glycerol is a residue of biodiesel production process. It can be used to produce biogas through an anaerobic digestion process $(4,5)$. To improve the anaerobic digestion process, pretreatments are being studied (6). The aim of this work was to investigate the effect of ultrasound (US) pretreatment in crude glycerol to produce biogas and with this, present an alternative for the production of renewable energy. 
Materials and methods. To carry out the anaerobic digestion process, anaerobic sludge collected from septic tanks of rural area of Bragança, Portugal, was used as inoculum. The substrate evaluated was crude glycerol from the biodiesel production process obtained from the Laboratory of Biofuels, Management and Technology School, Polytechnic Institute of Bragança. The physicochemical characterization of the inoculum and the substrate was performed according to (8) procedures for total solids (TS), fixed solids (FS), volatile solids (VS) and chemical oxygen demand (COD).

Crude glycerol was treated in an ultrasonic bath of $50 \mathrm{kHz}$. Different times of pretreatment were tested, 15 and 30 minutes. After pretreatment, glycerol was filled in the reactors to produce biogas. In addition, a test with untreated glycerol was performed to compare the effect of the time of the ultrasound pretreatment.

The anaerobic digestion process was tested on batch reactors $(250 \mathrm{ml})$ system for 23 days under mesophilic conditions $\left(37^{\circ} \mathrm{C}\right)$. Reactors were filled with $200 \mathrm{ml}$ of a mixture of inoculum and substrate (untreated glycerol, glycerol with 15-minute and 30-minute of pretreatment). Each reactor had a rubber in its stopper that allowed to measure biogas by moving with gas pressure the plunger of a syringe. The tests were performed in triplicate and the biogas volume produces were daily measured. The system of reactors is shown in Figure 1.

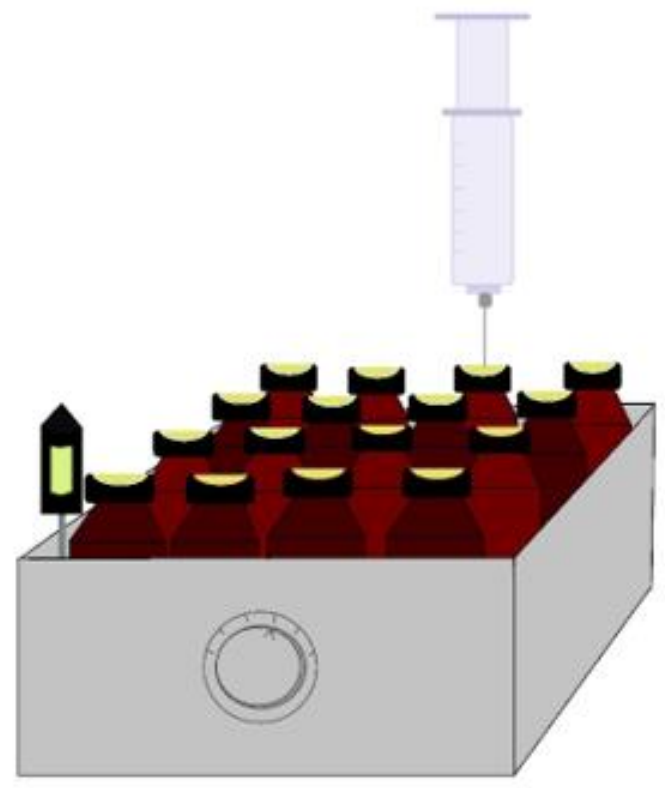

Figure 1. System of rectors to produce the biogas with the syringe and the thermometer.

This test was carried out until the biogas volume produced dropped below the $1 \%$ of its accumulated production value. The biogas volume produced by the inoculum was discounted using a control system, so the results allowed us to evaluate the pretreatment effect in the crude glycerol.

Results. Values obtained for the physicochemical characterization of the content on the reactors are shown in the Table 1. Due to the increase in pretreatment time, total solids decreased. It could 
be associated to the solubilization of the glycerol produced by the pretreatment. COD values increased demonstrating that the organic matter was disintegrated as described in (8) in its studies made on activated sludge.

Table 1. Average values of the physicochemical characterization to the content of reactors after anaerobic digestion process.

\begin{tabular}{l|lll} 
& Without treatment & $\mathbf{1 5}$ min of US & $\mathbf{3 0 ~} \mathbf{m i n}$ of US \\
\hline TS $[\mathrm{g} / \mathrm{ml}]$ & 29.8 & 24.0 & 22.9 \\
FS $[\mathrm{g} / \mathrm{ml}]$ & 8.1 & 1.9 & 3.1 \\
VS [g/ml] & 21.7 & 22.1 & 19.8 \\
COD [g/l] & 22.4 & 25.64 & 39.0 \\
\hline
\end{tabular}

Daily biogas production is graphically depicted in figure 2. Each curve represents the methane accumulated volume produced by treatment.

The results showed that the maximum production was reached by the reactors that who underwent 30 -minute of pretreatment, with $2,021 \mathrm{ml}$ of biogas, followed by 15 -minute ultrasound treatment $(1,356.6 \mathrm{ml}$ of biogas) and, finally, the reactors whose glycerol was not ultrasonically treated, with $1,010.5 \mathrm{ml}$ of biogas produced.

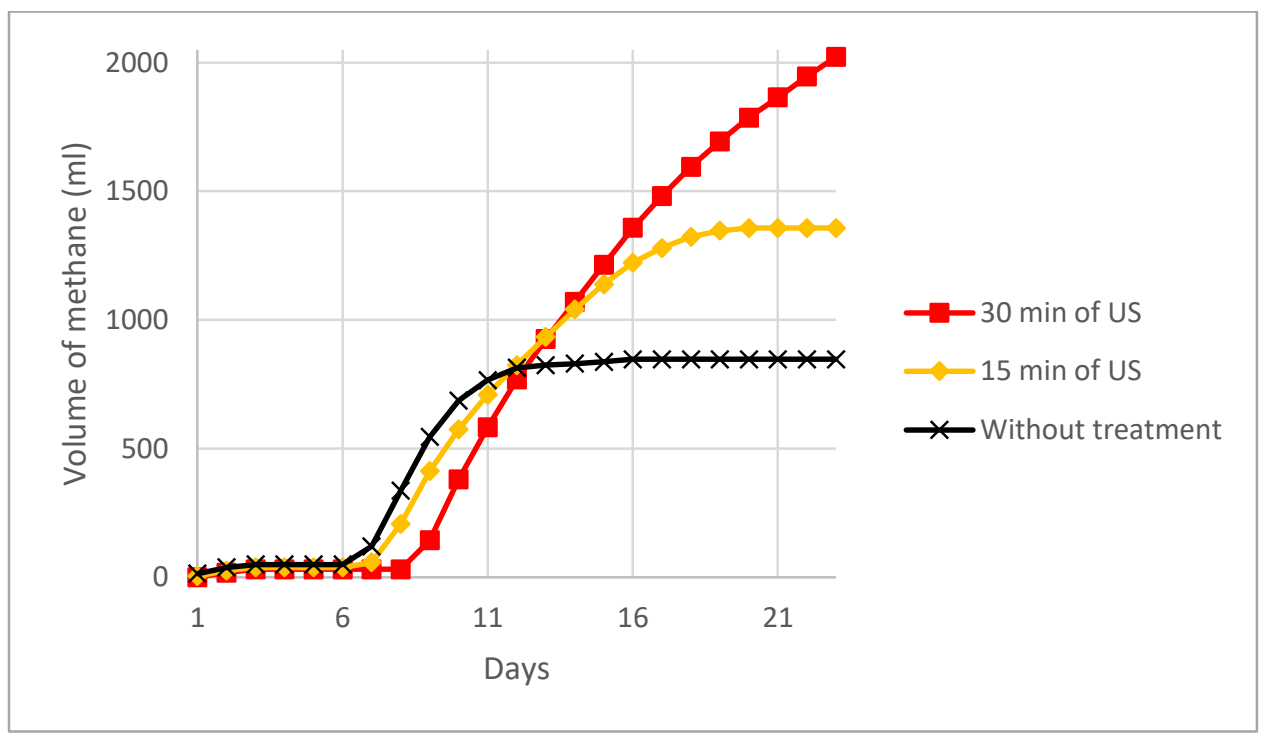

Figure 2. Accumulated biogas production from crude glycerol. 
Studies made by $(8,10)$ shows that the best results, in terms of biogas production, were achieved by the substrate that had the longest ultrasound pretreatment time. The authors realized a codigestion using maize straw and dairy manure and sewage sludge as substrates. The ultrasound treatment showed to enhance methane production, one of the main components of biogas, in crude glycerol according to (11), when mixed with activated sludge treated.

There are not studies made in crude glycerol and similar conditions as the perform on this work, however, all published studies about ultrasound pretreatments carried out on substrates agree that with time increment, the biogas volume produced also increases.

Conclusion. The results showed that the ultrasound pretreatment improves biogas production. With the increase in pretreatment time, total solids decreased and COD values increased, describing a process of solubilization in organic matter. The comparison between ultrasound pretreatment times showed that the 30-minute pretreatment had the best performance when obtaining $2,021 \mathrm{ml}$ of biogas against the $1,010.5 \mathrm{ml}$ produced by the substrate that was not treated.

Acknowledgments. This work was financially supported by the Associate Laboratory LSRELCM - UID/EQU/50020/2019 - funded by national funds of Portugal through FCT/MCTES (PIDDAC).

Disclosure. The authors report no conflicts of interest in this work.

\section{References.}

(1) Dincer, I. (2000). Renewable energy and sustainable development: a crucial review. Renewable and Sustainable Energy Reviews, 4(2), 157-175. https://doi.org/10.1016/S1364-0321(99)00011-8. (2) Lund, H. (2007). Renewable energy strategies for sustainable development. Energy, Elseiver, 32(6), 912-919. https://doi.org/10.1016/j.energy.2006.10.017.

(3) Demirbas A. (2009) Political, economic and environmental impacts of fuels: A review. Applied Energy 86 (2009) 108-117. 09 https://doi.org/10.1016/j.apenergy.2009.04.036.

(4) Ormaechea, P., Castrillón, L., Marañón, E., Fernández-Nava, Y., Negral, L., \& Megido, L. (2016). Influence of the ultrasound pretreatment on anaerobic digestion of cattle manure, food waste and crude glycerine. Environmental Technology, 38(6), 682-686. https://doi.org/10.1080/09593330.2016.1208278.

(5) Viana, M., Freitas, A., Leitão, R., Pinto, G., \& Santaella, S. (2012). Anaerobic digestion of crude glycerol: a review. Environmental Technology Reviews, 1(1), 81-92. https://doi.org/10.1080/09593330.2012.692723.

(6) Wu-Haan, W. (2008). Evaluation of ultrasonic pretreatment on anaerobic digestion of biomass for methane production (Master in Science). Iowa State University. https://lib.dr.iastate.edu/edt/11645.

(7) Santibáñez, C., Varnero, M., \& Bustamante, M. (2011). Residual Glycerol from Biodiesel Manufacturing, Waste or Potential Source of Bioenergy: A Review. Chilean Journal Of Agricultural Research, 71(3), 469-475. https://doi.org/10.4067/S0718-58392011000300019.

(8) Grönroos, A., Kyllönen, H., Korpijärvi, K., Pirkonen, P., Paavola, T., Jokela, J., \& Rintala, J. (2005). Ultrasound assisted method to increase soluble chemical oxygen demand (SCOD) of 
sewage sludge for digestion. Ultrasonics Sonochemistry, 12(1-2), 115-120. https://doi.org/10.1016/j.ultsonch.2004.05.012.

(9) Wilkie, A. (2003) Anaerobic Digestion of Flushed Dairy Manure. Proceedings - Anaerobic Digester Technology Applications in Animal Agriculture- A National Summit, p.350-354. Water Environment Federation, Alexandria, Virginia. https://biogas.ifas.ufl.edu/Publs/WEF-WilkieJune2003.pdf

(10) Zou, S., Wang, X., Chen, Y., Wan, H., \& Feng, Y. (2015). Enhancement of biogas production in anaerobic co-digestion by ultrasonic pretreatment. Energy Conversion and Management 112 (2016) 226-235. https://doi.org/10.1016/j.enconman.2015.12.087.

(11) Paulista, L.O., Boaventura, R.A.R., Vilar, V.J.P. et al. Enhancing methane yield from crude glycerol anaerobic digestion by coupling with ultrasound or A. niger/E. coli biodegradation. Environ Sci Pollut Res 27, 1461-1474 (2020). https://doi.org/10.1007/s11356-019-06748-w. 